Article

\title{
Highly Stable Inverted CdSe/ZnS-Based Light-Emitting Diodes by Nonvacuum Technique ZTO as the Electron-Transport Layer
}

\author{
Sajid Hussain 1,+® , Fawad Saeed ${ }^{1,+}{ }^{\oplus}$, Ahmad Raza $^{1}{ }^{1}$, Abida Parveen $^{1}$, Ali Asghar ${ }^{1}$, Nasrud Din ${ }^{1}$, \\ Zhang Chao ${ }^{2}$, Jing Chen ${ }^{1, *}$, Qasim Khan ${ }^{1,3, *}$ (1) and Wei Lei ${ }^{1, *}$ \\ 1 Joint International Laboratory of Information Display and Visualization, School of Electronic Science and \\ Engineering, Southeast University, Nanjing 210096, China; 233189934@seu.edu.cn (S.H.); \\ 233199956@seu.edu.cn (F.S.); ahmadraza@seu.edu.cn (A.R.); 101300071@seu.edu.cn (A.P.); \\ ali_pk@seu.edu.cn (A.A.); nasruddin@seu.edu.cn (N.D.) \\ 2 The Key Laboratory of MEMS of the Ministry of Education, School of Electronic Science and Engineering, \\ Southeast University, Nanjing 210096, China; chao_zhang@seu.edu.cn \\ 3 Institute of Microscale Optoelectronics, Shenzhen University, Shenzhen 518000, China \\ * Correspondence: chenjing@seu.edu.cn (J.C.); qasim@szu.edu.cn (Q.K.); lw@seu.edu.cn (W.L.); \\ Tel./Fax: +86-25-83363222 (W.L.) \\ + These authors contributed to the manuscript equally.
}

\section{check for} updates

Citation: Hussain, S.; Saeed, F.; Raza, A.; Parveen, A.; Asghar, A.; Din, N.; Chao, Z.; Chen, J.; Khan, Q.; Lei, W. Highly Stable Inverted CdSe/ZnS-Based Light-Emitting Diodes by Nonvacuum Technique ZTO as the Electron-Transport Layer. Electronics 2021, 10, 2290. https:/ / doi.org/10.3390/electronics10182290

Academic Editor: Antonio Di Bartolomeo

Received: 13 August 2021

Accepted: 7 September 2021

Published: 17 September 2021

Publisher's Note: MDPI stays neutral with regard to jurisdictional claims in published maps and institutional affiliations.

Copyright: (c) 2021 by the authors. Licensee MDPI, Basel, Switzerland. This article is an open access article distributed under the terms and conditions of the Creative Commons Attribution (CC BY) license (https:/ / creativecommons.org/licenses/by/ $4.0 /)$.

\begin{abstract}
CdSe/ZnS quantum dots (QDs) have attracted great consideration from investigators owing to their excellent photo-physical characteristics and application in quantum dot light-emitting diodes (QD-LEDs). The CdSe/ZnS-based inverted QD-LEDs structure uses high-quality semiconductors electron transport layers (ETLs), a multilayered hole transporting layers (HTLs). In QD-LED, designing a device structure with a minimum energy barrier between adjacent layers is very important to achieve high efficiency. A high mobility polymer of poly (9,9-dioctylfluorene-co-N-(4-(3-methylpropyl)) diphenylamine (TFB) was doped with 4,4'-bis-(carbazole-9-yl) biphenyl (CBP) with deep energy level to produce composite TFB:CBP holes to solve energy mismatch (HTL). In addition, we also improved the QD-LED device structure by using zinc tin oxide (ZTO) as ETL to improve device efficiency. The device turn-on voltage $\mathrm{Vt}\left(1 \mathrm{~cd} \mathrm{~m}^{-2)}\right.$ with ZTO ETL reduced from $2.4 \mathrm{~V}$ to $1.9 \mathrm{~V}$ significantly. Furthermore, invert structure devices exhibit luminance of $4296 \mathrm{~cd} \mathrm{~m}^{-2}$, current-efficiency (CE) of $7.36 \mathrm{~cd} \mathrm{~A}^{-1}$, and external-quantum efficiency (EQE) of 3.97\%. For the QD-LED based on ZTO, the device efficiency is improved by 1.7 times.
\end{abstract}

Keywords: light-emitting diode; Zinc tin oxide; composite hole transport layer; CdSe/ZnS

\section{Introduction}

In recent years, Quantum dots (QDs) have attracted considerable attention as an active material because of their excellent optoelectrical properties, such as broadband absorption, bandgap turnability, narrow full-width half maximum (FWHM), high photoluminescence (PL), inherent photo-physical stability, and their advanced optoelectronic application in QD based light-emitting diodes (QD-LEDs) [1-5]. The CdSe/ZnS core-shell is a kind of QDLEDs that have a wide variety of applications because of their remarkable stability, solutionprocessability, color tunability, and good efficiency [6,7]. However, there are still some issues that need to be resolved, such as high turn-on $\left(V_{T}\right)$ voltage, low device efficiency in the feasible brightness range, and surface trap-states of QDs, which are caused by ineffective carrier injection in the emission layer and a deprived electron-hole balance inside the structure [8-11]. In general for inverted CdSe/ZnS QD-LEDs, Fluorine-tin oxide (FTO) coated glass has been used as a bottom substrate, zinc oxide nanoparticles (ZnO NPs) act as electron transport layer (ETL), poly(3,4-ethylenedioxythiophene) polystyrene sulfonate (PEDOT:PSS) acts as hole injection layer (HIL) [12,13], poly(9-vinlycarbazole) (PVK) [14] and/or poly[N,Ni-bis(4-butylphenyl)-N,Nibisphenylbenzidine) (poly-TPD) $[15,16]$ are 
used for hole transporting layer (HTL), CdSe/ZnS QD acts as light-emissive layer (EML), and $\mathrm{Au}$ is deposited as top electrode $[17,18]$.

Metal oxides such as zinc tin oxide (ZTO), titanium dioxide $\left(\mathrm{TiO}_{2}\right)$, and zinc oxide nanoparticles ( $\mathrm{ZnO}$ NPs) have been utilized as ETLs to enhance electron injection and charge balance in the QD EML $[19,20]$. In comparison to organic compounds, inorganic compounds such as metal oxides have high thermal stability and resistance to oxygen and moisture. Among several metal oxide ETL materials, solution-processed ZnO NPs outperformed other vacuum-deposited metal oxides in QD-LEDs. There are still some difficulties with solution-processed metal oxide ETLs; through the solution processing of two consecutive layers, an intermix might develop, resulting in a leakage current inside the structure $[21,22]$.

Furthermore, the exciton quenching action may be caused by the hydroxyl bond $(\mathrm{O}-\mathrm{H})$ generated during the solution process. As a result, ZTO has been investigated as an ETL material for QD-LEDs to build an efficient inorganic ETL. ZTO's nature as a compoundbased $\mathrm{ZnO}$ and $\mathrm{SnO}_{2}$ energy band characteristics have in-between values of $\mathrm{ZnO}$ and $\mathrm{SnO}_{2}$, and these qualities might contribute to enhancements in ETL electron transport/injection and hole blocking layer [21]. In contrast to the highest occupied molecular orbital (HOMO) and lowest unoccupied molecular orbital (LUMO) energy levels of conventional conjugated organic molecules or polymers (5.5 and $3 \mathrm{eV}$, respectively), QDs have a lower valence band (VB) $(6$ to $7 \mathrm{eV})$ and conduction band (CB) $(4$ to $5 \mathrm{eV})$ energy levels [23-25]. Injecting holes from the organic layer into QDs has a high potential energy barrier (greater than $1 \mathrm{eV}$ ), but electrons can easily insert into QDs. As a result, the active charge transfer mechanism is hampered, resulting in excessive charge injection. Unbalanced charge injection causes undesirable auger recombination, such as leakage current and device heating, reducing device performance [25].

However, high hole mobility HTLs such as poly(9,9-dioctylfluorene-co-N-(4-butyl phenyl) diphenylamine) (TFB) [26,27] and 4,4í-bis(carbazole-9-yl) biphenyl (CBP) [28,29] were investigated to increase the hole mobility and reduce the potential barrier between the HTL and QD EML, resulting in improved overall device performance [15,30]. Furthermore, it was shown that such composite HTLs could improve hole transport mobility and form a stepwise energy level for hole injection in the device by combining the high mobilities of TFB and the deep-lying HOMO level of CBP, which promotes charge carrier transport balance, reduces multi HTLs into a single layer, and injects holes in QDs [31].

To enhance the device performance, we successfully designed and fabricated the inverted QD-LED by using composite HTL TFB:CBP 4:1 [31] and solution-processed ZTO as ETL. By using these strategies, the charge balance and interfacial interaction among the transporting and active layers were effectively improved. By compiling these ideas, the devices showed a low $\left(\mathrm{V}_{\mathrm{T}}\right)$ of $1.9 \mathrm{~V}$ and maximum luminance of $4296 \mathrm{~cd} \mathrm{~m}^{-2}$ at a current efficiency (CE) of $7.36 \mathrm{~cd} \mathrm{~A}^{-1}$. We are confident that this structural optimization has laid the groundwork for the design phase of hybrid QD-LEDs and the identification of next-generation QD-LED-based display and lighting technologies that demand high resolution and low production costs.

\section{Materials and Methods}

\subsection{Synthesis}

CdSe/ZnS core-shell QDs were synthesized according to the previously reported method with minor modification [32-34]. Briefly, 2 mmol of Cadmium Oxide (CdO), $3 \mathrm{mmol}$ zinc acetate, $6 \mathrm{~mL}$ Oleic acid (OA), and $25 \mathrm{~mL}$ octadecene (ODE) were mixed into a $100 \mathrm{~mL}$ round flask, heated to $160{ }^{\circ} \mathrm{C}$, filled $\mathrm{N}_{2}$ with vigorous stirring, degassed and further heated to $280^{\circ} \mathrm{C}$ to obtain the clear solution of $\mathrm{Cd}(\mathrm{OA})_{2}$ and $\mathrm{Zn}(\mathrm{Ac})_{2}$. At $280^{\circ} \mathrm{C}, 0.4 \mathrm{mmol}$ of selenium (Se), $4 \mathrm{mmol}$ sulfur (S) powder dissolved together in $3 \mathrm{~mL}$ Trioctylphospine (TOP) for $5 \mathrm{~min}$ at $100{ }^{\circ} \mathrm{C}$, were injected rapidly into the reaction flask. After injection was over, the temperature was maintained at $280^{\circ} \mathrm{C}$ for $20 \mathrm{~min}$. Then, $0.6 \mathrm{~mL}$ dodecanthiol (DDT) was added dropwise at the rate of $1 \mathrm{~mL} \mathrm{~min}^{-1}$ for another $10 \mathrm{~min}$. 
Finally, the mixture was cooled to room temperature to produce the red CdSe/ZnS QDs using an ice bar. For purification, acetone and chloroform were added to the suspensions, followed by centrifugation at 10,000 rpm for $10 \mathrm{~min}$ and dissolved in octane for further use. $\mathrm{ZnO}$ NPs were synthesized according to the reported method [35,36]. ZTO was synthesized according to the following reported articles after some modification [37]. $\mathrm{ZnCl}_{2}$ and $\mathrm{SnCl}_{2}$ were selected as the zinc and tin precursors. Ethanol was used due to its environmentally friendly solvent. The $\mathrm{ZnO}$ precursor solution was prepared by dissolving $0.2 \mathrm{M}(0.136 \mathrm{~g})$ $\mathrm{ZnCl}_{2}$ in ethanol. $0.2 \mathrm{M}(0.225 \mathrm{~g}) \mathrm{SnCl}_{2}$ was dissolved in ethanol and stirred at $60{ }^{\circ} \mathrm{C}$ to form a $\mathrm{SnO}_{2}$ precursor solution. To form a $\mathrm{ZTO}$ precursor solution, we mixed $\mathrm{ZnO}$ and $\mathrm{SnO}_{2}$ precursor solution at the molar ratio of 1:1. Before use, the precursor solution was stirred for $2 \mathrm{~h}$ and filtered through a $0.22 \mu \mathrm{m}$ nylon syringe filter.

\subsection{Device Fabrication}

First, detergent, deionized water, acetone, ethanol, and isopropyl alcohol were used to clean Fluorine-doped Tin oxide (FTO) patterned glass in an ultrasonication bath for $15 \mathrm{~min}$. The ZTO precursor solution as ETL spin-coated at $2000 \mathrm{r} / \mathrm{min}$ for $60 \mathrm{~s}$ and sintered at $180{ }^{\circ} \mathrm{C}$ for $10 \mathrm{~min}$. Then, CdSe/ZnS QD $\left(10 \mathrm{mg} \mathrm{mL}^{-1}\right.$ in octane) was spin-coated on the deposited ZTO layer at $1500 \mathrm{r} / \mathrm{min}$ for $30 \mathrm{sec}$ and sintered for $10 \mathrm{~min}$ at $120^{\circ} \mathrm{C}$. Afterward, hybrid HTL (10 $\mathrm{mg} \mathrm{mL}^{-1}$ in chlorobenzene) TFB:CBP = 4:1 was spin-coated on the QD film at $2500 \mathrm{r} / \mathrm{min}$ for $40 \mathrm{sec}$ and annealed at $120{ }^{\circ} \mathrm{C}$ for $15 \mathrm{~min}$. In the end, Au (electrode) was deposited by thermal deposition via a shadow mask. Our fabricated device has a $0.04 \mathrm{~cm}^{-2}$ emission zone.

\subsection{Device Characterization}

Field emission electron microscopy (FESEM, Quanta 200, FEI: Hillsboro, OR, USA) is used to measure the thickness of the layer. Smartlab-3 diffractometer was used to obtain the X-ray diffraction (XRD) results. FEI Tecnai-G20 was used to take tunneling electron microscope (TEM) and the high-resolution (HR) TEM images. UV-vis spectrophotometer (UV-1780, SHIMADZU) was used to measure the absorption of the samples. EDINBURGH(FS5) system used to measure photoluminance (PL) and quantum yield (QY). KEITHLEY 2400 and Spectrascan (PR 670) instruments were used to optimize the optoelectronic properties of the QLED device. The optimizations were carried out under an ambient atmosphere.

\section{Results and Discussion}

Figure 1a (inset), represents high-resolution transmission electron microscopy (HRTEM) and TEM images of CdSe/ZnS QDs with a particle size of $10 \mathrm{~nm}$, a spherical shape, and homogenous size distribution. Figure $1 \mathrm{a}$ displays a distinct lattice structure with a d-spacing of $0.4 \mathrm{~nm}$, which is consistent with the literature and indicates strong crystallinity in the synthesized QDs [38]. The X-ray diffraction (XRD) pattern in Figure 1b indicates that the diffraction peaks (111), (221), and (311) belong to the cubic phase of the synthesized CdSe/ZnS QDs [39]. The UV-vis-absorption and PL spectra of the fabricated QDs (in solution) are shown in Figure 1c. The absorption and luminescence peaks of quantum dots are monitored at $630 \mathrm{~nm}$ and $620 \mathrm{~nm}$, corresponding to red light emission. The full width at half peak (FWHM) is $30 \mathrm{~nm}$, and the calculated PLYQ of QDs dots (in solution) is 80\% and $31 \%$ (film state), respectively. 


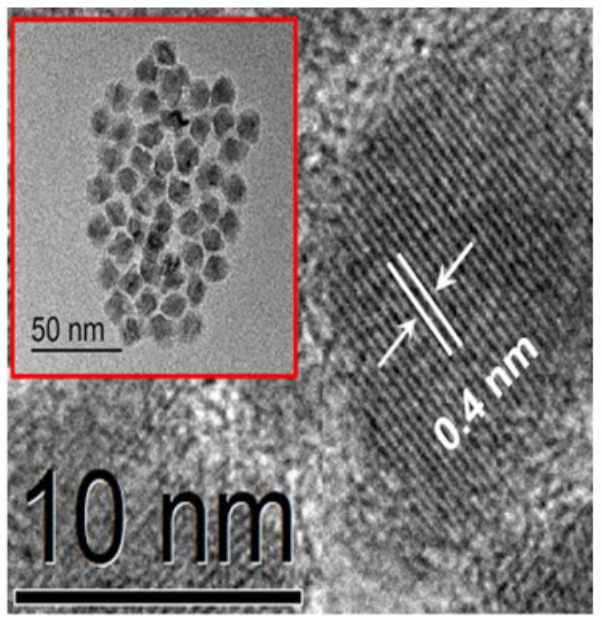

(a)

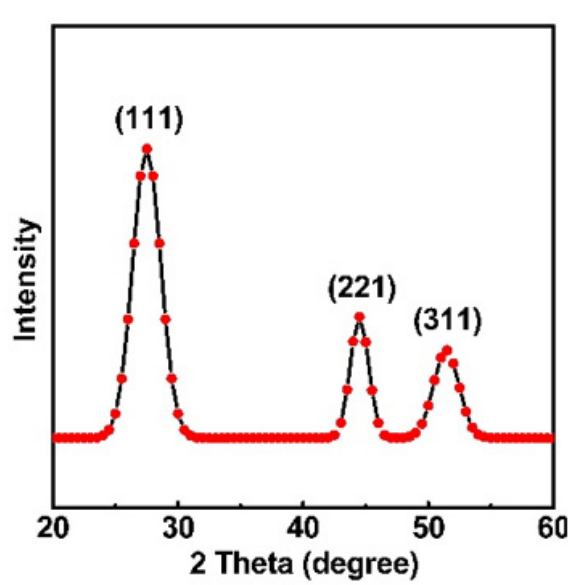

(b)

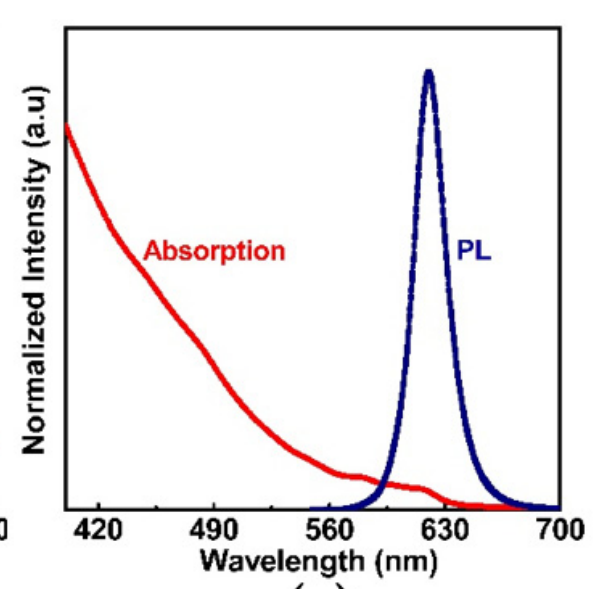

(c)

Figure 1. Characteristics of CdSe/ZnS core-shell QDs; (a) HRTEM and TEM images; (b) XRD pattern; and (c) UV-vis absorption and PL spectra.

Roughness and morphology strongly affect the suitable interface contact and efficient charge flow through the interfaces. Atomic force microscopy (AFM) height images of ZTO films on plane ITO substrate were taken and shown in Figure 2a (Figure 2b showed a threedimensional surface topography image). The prepared ZTO film represents roughness on route mean square (RMS) $7.01 \mathrm{~nm}$ at $180{ }^{\circ} \mathrm{C}$. The small RMS value of ZTO (film state) can describe the tiny grain size and flatter surface, which could passivate the surface defects, reduce the contact resistance, and improve the morphology of active layers. All of the above can be defined as reducing the fabricated device's leakage current and principal for better device performance. The XRD patterns are also illustrated of ZTO film in Figure 2c. Only one peak showed on the ZTO phase, indicating that the fabricated ETL has an amorphous rather than crystalline structure. However, XRD exhibits a single peak at $32.5^{\circ}$, which means that precursors slightly impact the ZTO film's crystallinity in preparation conditions because the preparation method can control crystallinity. Therefore, the ZTO film shows an amorphous structure [40].

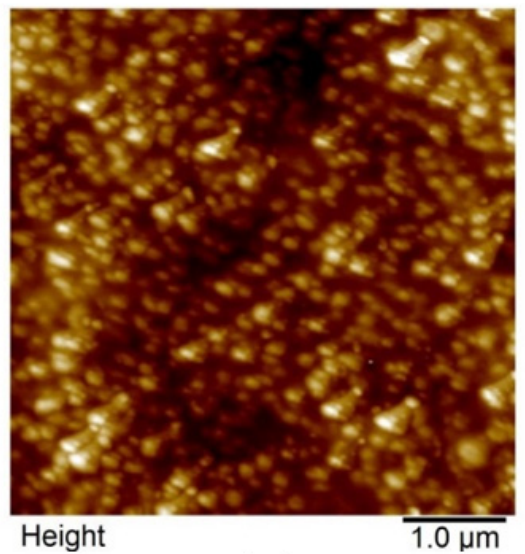

(a)

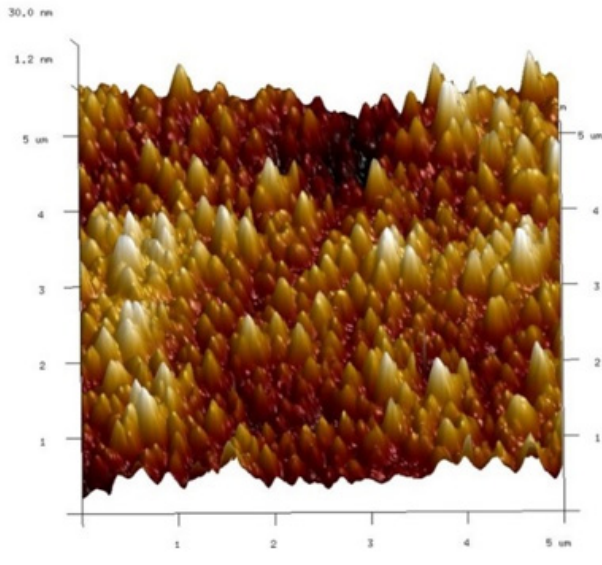

(b)

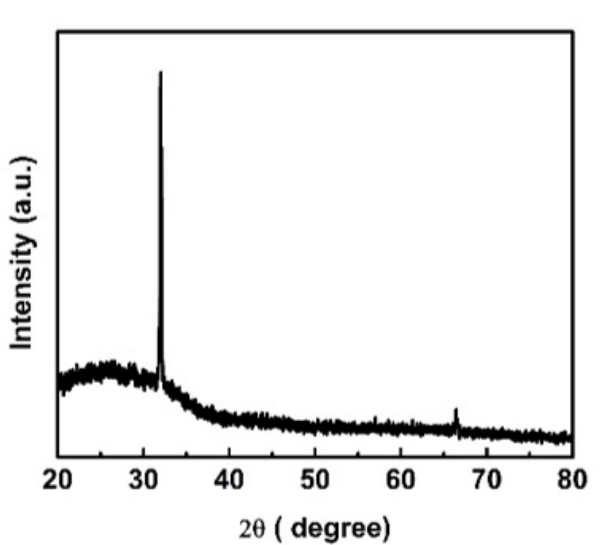

(c)

Figure 2. ZTO Characteristics (a) AFM height image; (b) 3D images; (c) XRD pattern.

The surface morphology of the ZTO with different layers is examined on plane ITO taken by SEM as shown in Figure 3a,b. A single layer of ZTO shows huge pinholes that cause the leakage current and increase the structure's heat, affecting the performance of the 
entire layers' interfaces. To overcome these issues, two layers of ZTO exhibit pinhole-free surface, which improved the performance of the QD-LED.

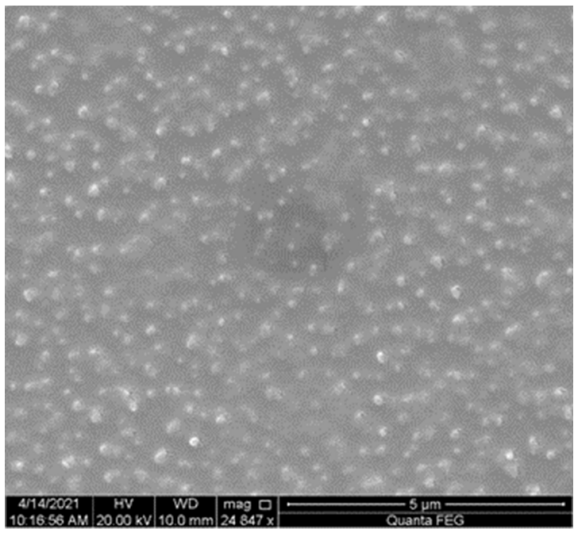

(a)

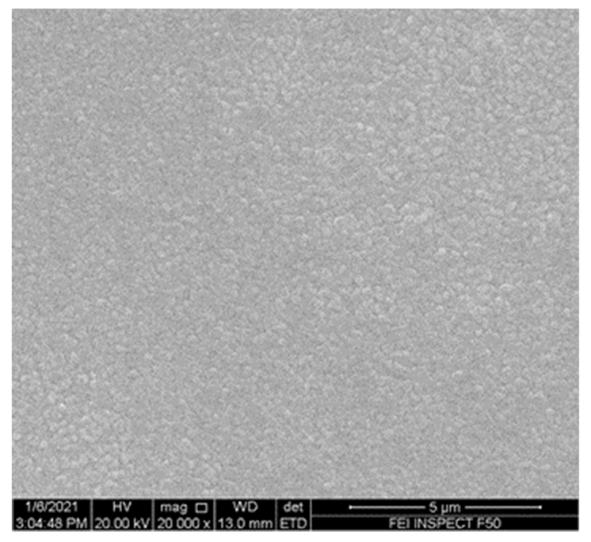

(b)

Figure 3. Scanning Electron microscopy (SEM) images; (a) one layer of ZTO; (b) two layers of ZTO.

The inverted QD-LED with hybrid HTL and solution-processed ETL was fabricated, as shown in Figure $4 \mathrm{a}$,b using the following structure; FTO/ZTO $(45 \mathrm{~nm}) / \mathrm{CdSe}-\mathrm{ZnS}$ $(40 \mathrm{~nm}) / \mathrm{TFB}: \mathrm{CBP}(50 \mathrm{~nm}) / \mathrm{Au}(100 \mathrm{~nm})$. To better charge insertion into EML, increase stability, and understand the working principle, composite HTL, and ZTO ETL were used. With an electron affinity of $4.0 \mathrm{eV}$ and an ionization potential of $\sim 7.2 \mathrm{eV}$, the ZTO layer allows more efficient electron transport from the FTO into QD, which acts to limit holes inside QD owing to their valance band offset at QD/ZTO interfaces, resulting in excellent charge recombination. Zn-Sn-O (ZTO) is kind of an n-type oxide material that combines $\mathrm{ZnO}$ and $\mathrm{SnO}_{2}$. Alternatively, composite HTL due to deep valance band, high hole mobility, and complex structure helps electron injection into QD. We fabricated an inverted QD-LED for a reference device with the following structure; ITO/ZnO/CdSeZnS/PVK/Poly-TPD/Au.

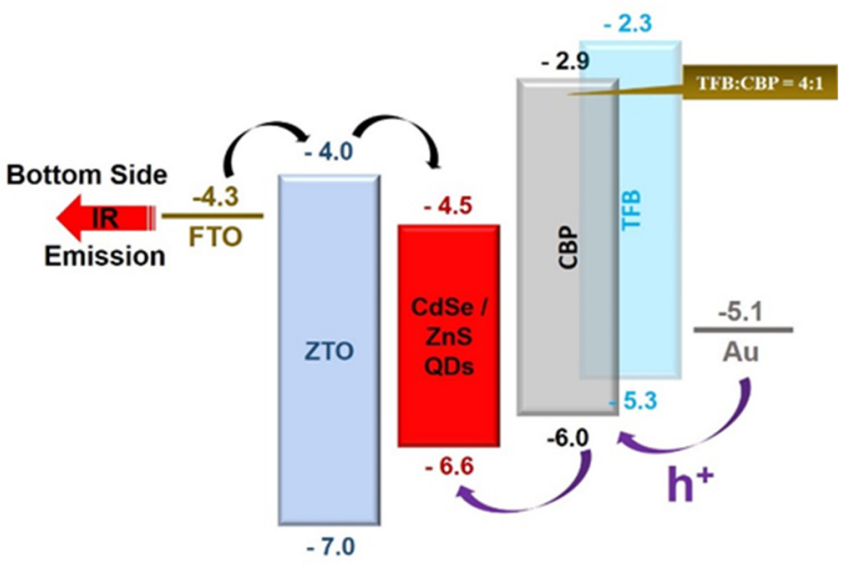

(a)

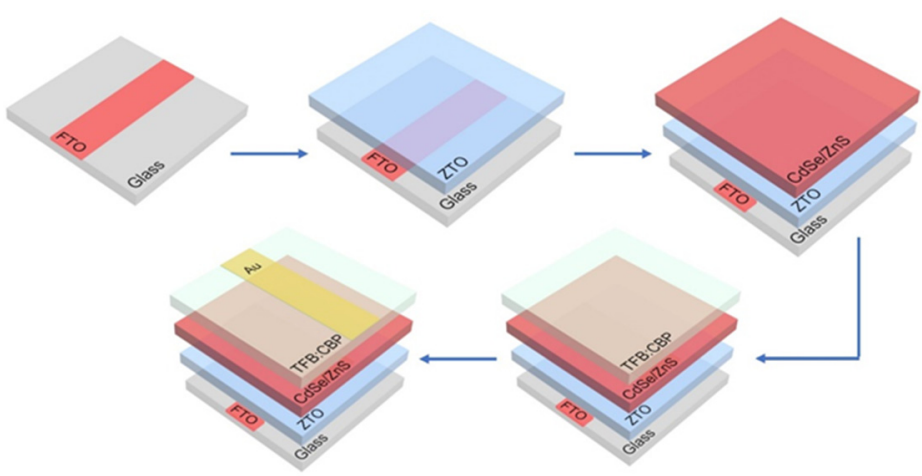

(b)

Figure 4. (a) Energy-level diagram of QD-based LED; (b) Schematic presentation of the fabrication of QD-LED.

The current density-voltage (J-V) characteristics of the QD-LED are shown in Figure 5a. QD-LED inverted structure with good efficiency was obtained with ZTO based ETL of the designed device as compared to the reference device. Reduced J of QD-LED devices through ZTO indicates better charge carrier injection from the ETL to the CdSe/ZnS QDs. Figure $5 \mathrm{~b}$ demonstrates that the ZTO-based LED has a slightly higher luminance than that 
of the LED with the reference device. In reference and as-designed devices, the turn-on voltage $\mathrm{V}_{\mathrm{T}}\left(1 \mathrm{~cd} \mathrm{~m}^{-2}\right)$ is $2.4 \mathrm{~V}$ and $1.9 \mathrm{~V}$, respectively, which proves an efficient injection and balanced structure in ZTO-based QD-LED. The maximum brightness of the inverted structure device is $4296 \mathrm{CD} \mathrm{m}^{-2}$ at $5 \mathrm{~V}$ (ZTO ETL) and $3146 \mathrm{CD} \mathrm{m}^{-2}$ at $7.5 \mathrm{~V}$ (ZnO ETL). A 1.7-factor enhancement in luminance was demonstrated due to the charge-balanced structure and stability of the designed inverted QD-LED. The as-designed device showed a significant increase in external quantum efficiency (EQE), as illustrated in Figure 5c. For inverted QD-LED devices, the EQE with ZTO and $\mathrm{ZnO}$ is 3.97\% and $2.91 \%$, respectively. The improvement in EQE ZTO-based QD-LED indicates the minimized leakage current. An incredible enhancement in current efficiency (CE) of $7.36 \mathrm{~cd} \mathrm{~A}^{-1}$ is found, as shown in Figure $5 d$, which is indicated to improve the charge balance and affect the device's performance. The performance of QD-LEDs as designed and reference devices is summarized in Table 1.

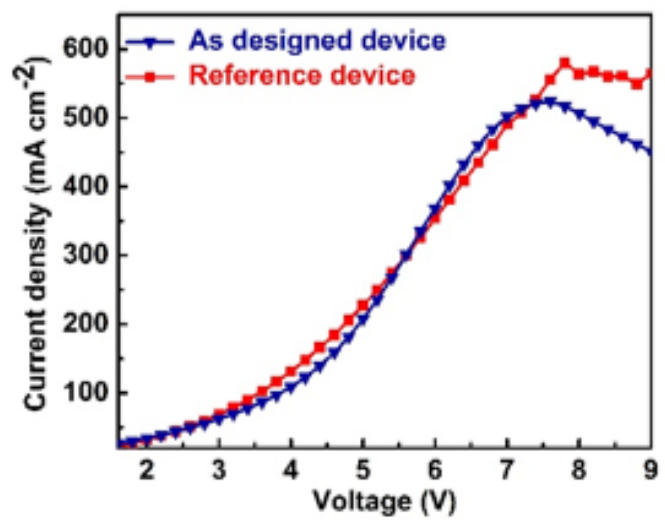

(a)

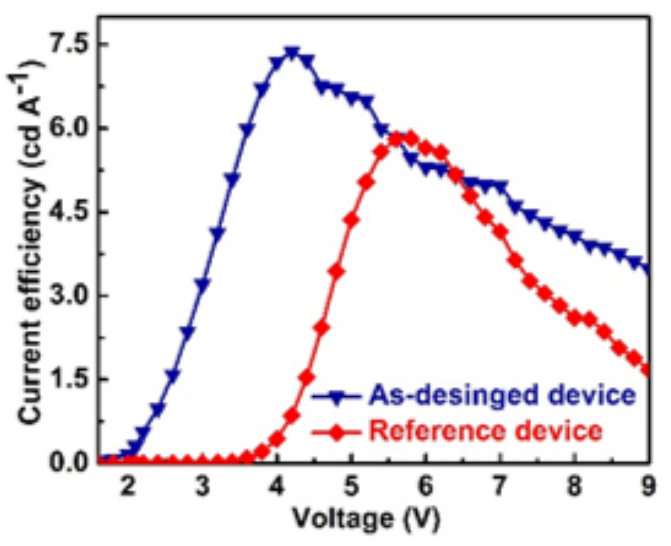

(c)

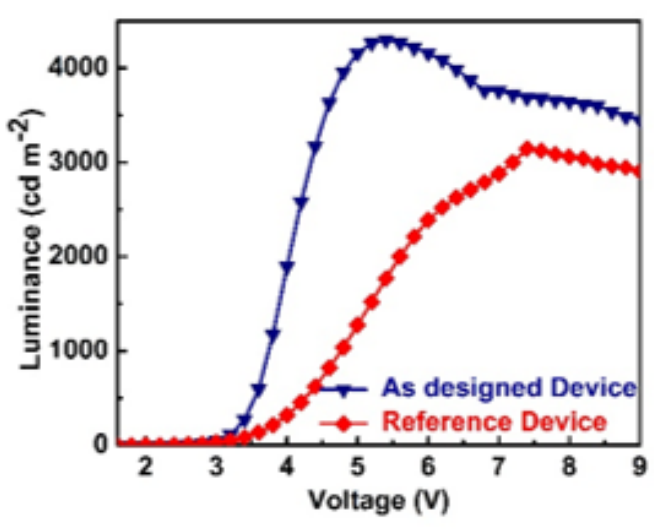

(b)

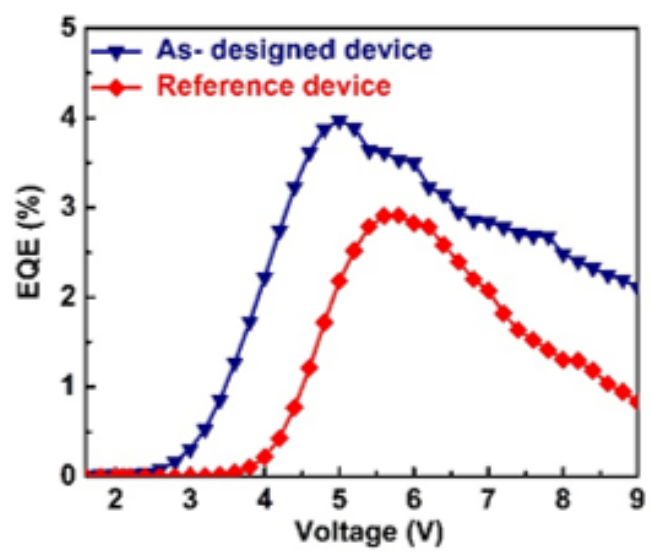

(d)

Figure 5. Comparisons results; (a) current density vs. voltage (V); (b) luminance vs. V; (c) current efficiency vs. V; (d) external quantum efficiency vs. V.

Table 1. Comparisons of the characteristics of the reference device and as-designed device.

\begin{tabular}{|c|c|c|c|c|}
\hline Device No. & Structure & \multicolumn{2}{|c|}{$V_{T}(V) L_{\max }\left(c^{-2} m^{-2}\right)$} & EQE (\%) \\
\hline Reference device & $\begin{array}{c}\mathrm{FTO} / \mathrm{ZnO} / \mathrm{CdSe}-\mathrm{ZnS} / \mathrm{PVK} / \text { Poly- } \\
\text { TBD/Au }\end{array}$ & 2.4 & 3146 & 2.91 \\
\hline As-designed device & $\begin{array}{l}\text { FTO/ZTO/CdSe- } \\
\text { ZnS/TFB:CBP/Au }\end{array}$ & 1.9 & 4296 & 3.97 \\
\hline
\end{tabular}


To confirm the effect of the carrier injection on charge transport, hybrid hole-only devices (HOD) and electron-only devices (EOD) were fabricated, and their J-V characteristics were measured as shown in Figure 6a They show well-balanced charge injection into QDs and equally, electron-hole recombination occurs and improves device performance. Without any encapsulation, the device's stability was optimized in natural conditions at $60 \%$ humidity.

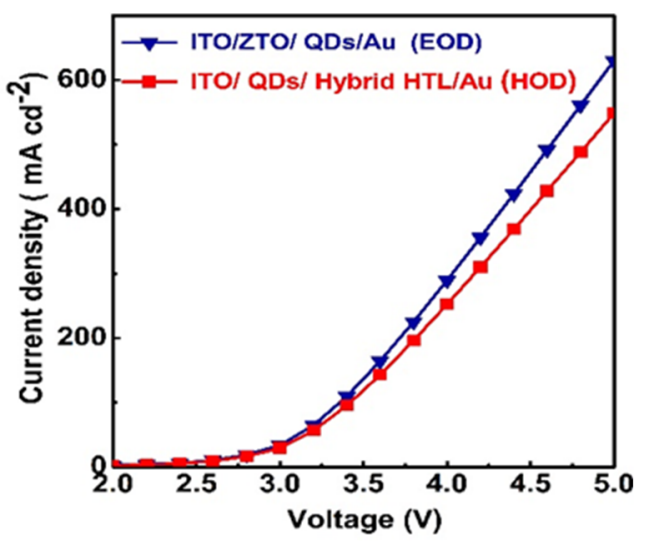

(a)

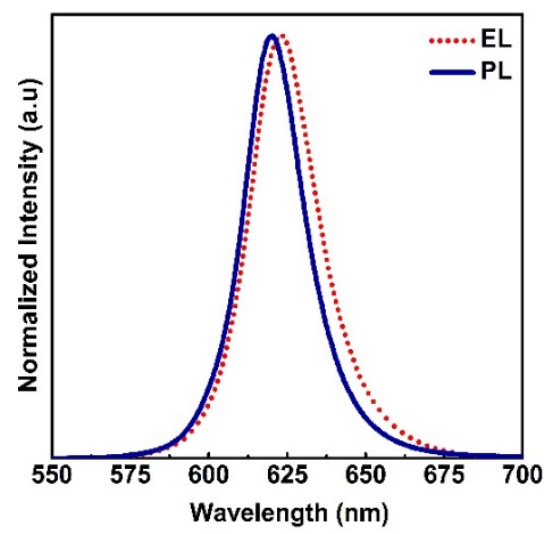

(b)

Figure 6. (a) HODs and EODs comparisons; (b) comparison of the EL spectrum of an as-designed device with the PL spectrum of the QDs in film state.

The PL of the QD (in film state) and the EL of the as-designed device are compared in Figure $6 \mathrm{~b}$. Because of the Stark effect and/or the Forster resonance energy transfer, the PL peak is blue-shifted from the EL peak.

\section{Conclusions}

In summary, we used CdSe/ZnS QDs to build inverted QD-LED devices with ZTO ETL and hybrid HTL. A composite layer of TFB polymer and the small molecule CBP was shown to be an excellent HTL for producing brilliant and efficient QD-LEDs. Taking advantage of TFB's high mobility and deep-seated HOMO CBP level, TFB:CBP composite HTL may increase hole handling ability and reduce the energy barrier for injecting holes into the device. The L-V analysis confirms that LED with ZTO ETL demonstrates a 1.7fold improvement compared to the reference LED. The QD-LED device with ZTO ETL showed a good luminance of $4296 \mathrm{~cd} \mathrm{~m}^{-2}$, a current efficiency of $7.36 \mathrm{~cd} \mathrm{~A}^{-1}$, and an $\mathrm{EQE}$ of $3.97 \%$. The proposed inverted QD-LED has a lower turn-on voltage (Vt) than the reference device, owing to better energy level matching and carrier injection into the QD emission layer. As a result, QD-LED devices will show benefits and new opportunities for optoelectronic devices such as photodetectors, field-effect transistors, and solar cells. In addition, the thorough investigation expands the potential for improving device stability and efficiency in real-world applications.

Author Contributions: Conceptualization, S.H. and W.L.; Data curation, S.H., F.S., Q.K. and W.L.; Formal analysis, S.H., F.S., A.P., A.A., N.D., Z.C., J.C., Q.K. and W.L.; Investigation, A.R. and J.C.; Methodology, S.H., A.R. and Q.K.; Visualization, S.H.; Writing-original draft, S.H. All authors have read and agreed to the published version of the manuscript.

Funding: This work is financially supported by the funding of the National Key Research and Development Program of China (2018YFE0125500, 2016YFB0401600).

Data Availability Statement: All data generated or analyzed during this study are included in this published article. 
Acknowledgments: This work is financially supported by the funding of the National Key Research and Development Program of China (2018YFE0125500, 2016YFB0401600), Program 111_2.0 in China (BP0719013), National Natural Science Foundation Project of China $(61775034,51879042$, 61674029, 12005038), Research Fund for International Young Scientists (62050410350), an international cooperative research project of Jiangsu province (BZ2018056), Leading Technology of Jiangsu Basic Research Plan (BK20192003), the Aeronautical Science Foundation of China (201951069001), and Jiangsu province college graduate research innovation program (KYLX16_0213).

Conflicts of Interest: The authors declare no competing financial interest.

\section{References}

1. Khan, Q.; Subramanian, A.; Yu, G.; Maaz, K.; Li, D.; Sagar, R.U.R.; Chen, K.; Lei, W.; Shabbir, B.; Zhang, Y. Structure optimization of perovskite quantum dot light-emitting diodes. Nanoscale 2019, 11, 5021-5029. [CrossRef]

2. Zhang, H.; Chen, S. An ZnMgO:PVP inorganic-organic hybrid electron transport layer: Towards efficient bottom-emission and transparent quantum dot light-emitting diodes. J. Mater. Chem. C 2019, 7, 2291-2298. [CrossRef]

3. Lee, M.H.; Chen, L.; Li, N.; Zhu, F. MoO3-induced oxidation doping of PEDOT:PSS for high performance full-solution-processed inverted quantum-dot light emitting diodes. J. Mater. Chem. C 2017, 5, 10555-10561. [CrossRef]

4. Mashford, B.S.; Stevenson, M.; Popovic, Z.; Hamilton, C.; Zhou, Z.; Breen, C.; Steckel, J.; Bulovic, V.; Bawendi, M.; Coe-Sullivan, S.; et al. High-efficiency quantum-dot light-emitting devices with enhanced charge injection. Nat. Photonics 2013, 7, 407-412. [CrossRef]

5. Coe, S.; Woo, W.K.; Bawendi, M.; Bulović, V. Electroluminescence from single monolayers of nanocrystals in molecular organic devices. Nature 2002, 420, 800-803. [CrossRef]

6. Zhao, J.; Bardecker, J.A.; Munro, A.M.; Liu, M.S.; Niu, Y.; Ding, I.K.; Luo, J.; Chen, B.; Jen, A.K.Y.; Ginger, D.S. Efficient CdSe/CdS quantum dot light-emitting diodes using a thermally polymerized hole transport layer. Nano Lett. 2006, 6, 463-467. [CrossRef] [PubMed]

7. Caruge, J.M.; Halpert, J.E.; Wood, V.; Buloví, V.; Bawendi, M.G. Colloidal quantum-dot light-emitting diodes with metal-oxide charge transport layers. Nat. Photonics 2008, 2, 247-250. [CrossRef]

8. Cho, K.S.; Lee, E.K.; Joo, W.J.; Jang, E.; Kim, T.H.; Lee, S.J.; Kwon, S.J.; Han, J.Y.; Kim, B.K.; Choi, B.L.; et al. High-performance crosslinked colloidal quantum-dot light-emitting diodes. Nat. Photonics 2009, 3, 341-345. [CrossRef]

9. Qian, L.; Zheng, Y.; Xue, J.; Holloway, P.H. Stable and efficient quantum-dot light-emitting diodes based on solution-processed multilayer structures. Nat. Photonics 2011, 5, 543-548. [CrossRef]

10. Kwak, J.; Bae, W.K.; Lee, D.; Park, I.; Lim, J.; Park, M.; Cho, H.; Woo, H.; Yoon, D.Y.; Char, K.; et al. Bright and efficient full-color colloidal quantum dot light-emitting diodes using an inverted device structure. Nano Lett. 2012, 12, 2362-2366. [CrossRef]

11. Bae, W.K.; Park, Y.S.; Lim, J.; Lee, D.; Padilha, L.A.; McDaniel, H.; Robel, I.; Lee, C.; Pietryga, J.M.; Klimov, V.I. Controlling the influence of Auger recombination on the performance of quantum-dot light-emitting diodes. Nat. Commun. $2013,4,3661$. [CrossRef]

12. Qasim, K.; Wang, B.; Zhang, Y.; Li, P.; Wang, Y.; Li, S.; Lee, S.T.; Liao, L.S.; Lei, W.; Bao, Q. Solution-Processed Extremely Efficient Multicolor Perovskite Light-Emitting Diodes Utilizing Doped Electron Transport Layer. Adv. Funct. Mater. 2017, $27,1606874$. [CrossRef]

13. Subramanian, A.; Pan, Z.; Zhang, Z.; Ahmad, I.; Chen, J.; Liu, M.; Cheng, S.; Xu, Y.; Wu, J.; Lei, W.; et al. Interfacial Energy-Level Alignment for High-Performance All-Inorganic Perovskite CsPbBr3 Quantum Dot-Based Inverted Light-Emitting Diodes. ACS Appl. Mater. Interfaces 2018, 10, 13236-13243. [CrossRef] [PubMed]

14. Dai, X.; Zhang, Z.; Jin, Y.; Niu, Y.; Cao, H.; Liang, X.; Chen, L.; Wang, J.; Peng, X. Solution-processed, high-performance light-emitting diodes based on quantum dots. Nature 2014, 515, 96-99. [CrossRef] [PubMed]

15. Son, D.I.; Kim, H.H.; Cho, S.; Hwang, D.K.; Seo, J.W.; Choi, W.K. Carrier transport of inverted quantum dot LED with PEIE polymer. Org. Electron. 2014, 15, 886-892. [CrossRef]

16. Liu, B.; Lan, L.; Liu, Y.; Tao, H.; Li, H.; Xu, H.; Zou, J.; Xu, M.; Wang, L.; Peng, J.; et al. Improved performance of quantum dot light-emitting diodes by hybrid electron transport layer comprised of $\mathrm{ZnO}$ nanoparticles doped organic small molecule. Org. Electron. Phys. Mater. Appl. 2019, 74, 144-151. [CrossRef]

17. Subramanian, A.; Akram, J.; Hussain, S.; Chen, J.; Qasim, K.; Zhang, W.; Lei, W. High-Performance Photodetector Based on a Graphene Quantum Dot/CH 3 NH 3 PbI 3 Perovskite Hybrid. ACS Appl. Electron. Mater. 2020, 2, 230-237. [CrossRef]

18. Hussain, S.; Raza, A.; Saeed, F.; Perveen, A.; Sikhai, Y.; Din, N.; Elemike, E.E. Stable and high performance all-inorganic perovskite light-emitting diodes with anti-solvent treatment. Chin. Opt. Lett. 2021, 19, 030005. [CrossRef]

19. Kim, D.J.; Lee, H.N. Improving the charge balance and performance of CdSe/ZnS quantum-dot light-emitting diodes with a sputtered zinc-tin-oxide electron-transport layer and a thermally evaporated tungsten-oxide charge-restricting layer. Jpn. J. Appl. Phys. 2019, 58, 106502. [CrossRef]

20. Kim, T.G.; Shin, D.S.; Jung, K.Y.; Kadam, A.N.; Park, J. Improving light extraction in light-emitting diodes using zinc-tin-oxide layers. J. Alloys Compd. 2017, 710, 399-402. [CrossRef] 
21. Park, M.; Roh, J.; Lim, J.; Lee, H.; Lee, D. Double metal oxide electron transport layers for colloidal quantum dot light-emitting diodes. Nanomaterials 2020, 10, 726. [CrossRef]

22. Joo, Y.H.; Wi, J.H.; Lee, W.J.; Chung, Y.D.; Cho, D.H.; Kang, S.; Um, D.S.; Kim, C. Il Work function tuning of zinc-tin oxide thin films using high-density o2 plasma treatment. Coatings 2020, 10, 1026. [CrossRef]

23. Ji, W.; Tian, Y.; Zeng, Q.; Qu, S.; Zhang, L.; Jing, P.; Wang, J.; Zhao, J. Efficient quantum dot light-emitting diodes by controlling the carrier accumulation and exciton formation. ACS Appl. Mater. Interfaces 2014, 6, 14001-14007. [CrossRef]

24. Cho, Y.R.; Kang, P.; Shin, D.H.; Kim, J.; Maeng, M.; Sakong, J.; Hong, J.; Park, Y.; Suh, M.C. Effect of anode buffer layer on the efficiency of inverted quantum-dot light-emitting diodes. Appl. Phys. Express 2015, 9, 012103. [CrossRef]

25. Lin, W.; Wu, J.L.; Zhang, Q.M.; Lei, Y.L.; Chen, L.X. High-performance full-solution-processed quantum dot lightemitting diodes with a doped hole injection layer. Sci. Sin. Phys. Mech. Astron. 2020, 50, 067301. [CrossRef]

26. Choi, M.K.; Yang, J.; Kim, D.C.; Dai, Z.; Kim, J.; Seung, H.; Kale, V.S.; Sung, S.J.; Park, C.R.; Lu, N.; et al. Extremely Vivid, Highly Transparent, and Ultrathin Quantum Dot Light-Emitting Diodes. Adv. Mater. 2017, 30, 1703279. [CrossRef]

27. Sun, Y.; Su, Q.; Zhang, H.; Wang, F.; Zhang, S.; Chen, S. Investigation on Thermally Induced Efficiency Roll-Off: Toward Efficient and Ultrabright Quantum-Dot Light-Emitting Diodes. ACS Nano 2019, 13, 11433-11442. [CrossRef] [PubMed]

28. Ding, K.; Fang, Y.; Dong, S.; Chen, H.; Luo, B.; Jiang, K.; Gu, H.; Fan, L.; Liu, S.; Hu, B.; et al. 24.1\% External Quantum Efficiency of Flexible Quantum Dot Light-Emitting Diodes by Light Extraction of Silver Nanowire Transparent Electrodes. Adv. Opt. Mater. 2018, 6, 1800347. [CrossRef]

29. Fang, Y.; Ding, K.; Wu, Z.; Chen, H.; Li, W.; Zhao, S.; Zhang, Y.; Wang, L.; Zhou, J.; Hu, B. Architectural Engineering of Nanowire Network Fine Pattern for 30 m Wide Flexible Quantum Dot Light-Emitting Diode Application. ACS Nano 2016, 10, 10023-10030. [CrossRef] [PubMed]

30. Son, D.I.; Kim, H.H.; Hwang, D.K.; Kwon, S.; Choi, W.K. Inverted CdSe-ZnS quantum dots light-emitting diode using low-work function organic material polyethylenimine ethoxylated. J. Mater. Chem. C 2014, 2, 510-514. [CrossRef]

31. Zhao, Y.; Chen, L.; Wu, J.; Tan, X.; Xiong, Z.; Lei, Y. Composite Hole Transport Layer Consisting of High-Mobility Polymer and Small Molecule with Deep-Lying HOMO Level for Efficient Quantum Dot Light-Emitting Diodes. IEEE Electron Device Lett. 2020, 41, 80-83. [CrossRef]

32. Khan, Q.; Subramanian, A.; Ahmed, I.; Khan, M.; Nathan, A.; Wang, G.; Wei, L.; Chen, J.; Zhang, Y.; Bao, Q. Overcoming the Electroluminescence Efficiency Limitations in Quantum-Dot Light-Emitting Diodes. Adv. Opt. Mater. 2019, 7, 1900695. [CrossRef]

33. Hussain, S.; Subramanian, A.; Yan, S.; Din, N.; Abbas, G.; Shuja, A.; Lei, W.; Khan, Q. Engineering Architecture of Quantum Dot-Based Light-Emitting Diode for High Device Performance with Double-Sided Emission Fabricated by Nonvacuum Technique. ACS Appl. Electron. Mater. 2020, 2, 2383-2389. [CrossRef]

34. Li, Y.; He, P.; Chen, S.; Lan, L.; Dai, X.; Peng, J. Inkjet-Printed Oxide Thin-Film Transistors Based on Nanopore-Free AqueousProcessed Dielectric for Active-Matrix Quantum-Dot Light-Emitting Diode Displays. ACS Appl. Mater. Interfaces 2019, 11, 28052-28059. [CrossRef]

35. Zhang, X.; Li, Q.; Yan, S.; Lei, W.; Chen, J.; Khan, Q. A Novel Phototransistor Device with Dual Active layers composited of $\mathrm{CsPbBr}_{3}$ and ZnO Quantum Dots. Materials 2019, 12, 1215. [CrossRef] [PubMed]

36. Beek, W.J.E.; Wienk, M.M.; Kemerink, M.; Yang, X.; Janssen, R.A.J. Hybrid zinc oxide conjugated polymer bulk heterojunction solar cells. J. Phys. Chem. B 2005, 109, 9505-9516. [CrossRef]

37. Zhang, Q.; Xia, G.; Li, L.; Xia, W.; Gong, H.; Wang, S. High-performance Zinc-Tin-Oxide thin film transistors based on environment friendly solution process. Curr. Appl. Phys. 2019, 19, 174-181. [CrossRef]

38. Mustafa, M.; Zubair, M.; Mustafa, M.; Lee, K.; Yoon, C.; Hoi, Y. Fabrication of CdSe/ZnS quantum dots thin film by electrohydrodynamics atomization technique for solution based flexible hybrid OLED application Fabrication of CdSe/ZnS quantum dots thin film by electrohydrodynamics atomization technique for solution. Chem. Eng. J. 2014, 253, 325-331. [CrossRef]

39. Chang, Y.; Sun, D.; Zhang, Z.; Zhang, Y.; Yao, X.; Jiang, D.; Yu, Y.; Mi, L.; Chen, L.; Zhong, H.; et al. High color-rendering-index Hybrid white LEDs employing CdSe/ZnS core/shell quantum dots. J. Nanosci. Nanotechnol. 2016, 16, 670-676. [CrossRef]

40. Zhao, Y.; Dong, G.; Duan, L.; Qiao, J.; Zhang, D.; Wang, L.; Qiu, Y. Impacts of Sn precursors on solution-processed amorphous zinc-tin oxide films and their transistors. RSC Adv. 2012, 2, 5307-5313. [CrossRef] 